\title{
Pessoas em situação de rua em Porto Alegre Processos de estigmatização e invisibilidade social
}

\author{
The homeless population in Porto Alegre
}

Social invisibility and stigmatization processes

Personas e situación callejera en Porto Alegre

Procesos de estigmatización e invisibilidad social

\author{
Melissa de Mattos Pimenta ${ }^{1}$
}

\begin{abstract}
Resumo: O artigo apresenta alguns dados sobre a população adulta em situação de rua em Porto Alegre, levantados no censo realizado por pesquisadores da Universidade Federal do Rio Grande do Sul em 2016, com apoio da Fundação de Assistência Social e Cidadania da Prefeitura Municipal. A pesquisa cadastrou 2.115 indivíduos adultos de ambos os sexos identificados como em "situação de rua" e efetuou entrevistas por meio de um questionário a uma amostra de 467 pessoas. No texto são apresentadas algumas características sociodemográficas dos adultos cadastrados e da amostra de entrevistados, comparando-as com os dados levantados nas pesquisas realizadas em 2007, 2008 e 2011. São discutidas as formas de ocupação do espaço urbano e os processos de estigmatização e invisibilidade social destas pessoas, traduzidos nos conflitos cotidianos com órgãos e instituições do estado que prestam serviços de assistência social, saúde e segurança pública e cidadãos domiciliados. Os dados apontam para o aumento do número de pessoas nessa condição em Porto Alegre, maior tempo de permanência na rua e envelhecimento desta população, o que levanta questões sobre as políticas públicas desenvolvidas para este segmento.
\end{abstract}

Palavras-chave: População adulta em situação de rua; Porto Alegre; Estigmatização; Invisibilidade social.

\begin{abstract}
The article presents part of the data on the adult homeless population in Porto Alegre, Rio Grande do Sul, gathered by researchers from the Federal University of Rio Grande do Sul in 2016, hired by the Social Assistance and Citizenship Foundation of the municipality of Porto Alegre. The research identified 2,115 homeless adults, both men and women, and a survey was applied to a sample of 467 people. In the article we present some of the social and demographic characteristics of the population and sample of interviewees, comparing data from previous surveys applied in 2007-2008 and 2011. We discuss how homeless people make use of urban structure, how they suffer "social invisibility" and stigmatization processes, focusing on daily life conflicts
\end{abstract}

\footnotetext{
${ }^{1}$ Universidade Federal do Rio Grande do Sul (Ufrgs, Porto Alegre, RS, Brasil). autora.dados_biográficos
}

Civitas, Porto Alegre, v. 19, n. 1, p. 82-104, jan.-abr. 2019 
with public institutions that offer social assistance, health care and public security services, as well as conflicts with "conventional" city dwellers. The results show that the homeless population in Porto Alegre has increased, aged and been longer on the streets, raising questions over the public policies for this social sector.

Keywords: Adult homeless population; Porto Alegre; Stigmatization; Social invisibility.

Resumen: El artículo presenta algunos datos sobre la población adulta en la situación callejera en Porto Alegre, planteada en el censo realizado por investigadores de la Universidad Federal de Rio Grande do Sul en 2016, con apoyo de la Fundación de asistencia social y ciudadanía de Ayuntamiento. La encuesta registró 2.115 individuos adultos de ambos sexos identificados como "situación callejera" y realizó entrevistas por medio de un cuestionario a una muestra de 467 personas. En el texto se presentan algunas características sociodemográficas de los adultos registrados y la muestra de los encuestados, en comparación con los datos planteados en las encuestas realizadas en 2007-2008 y 2011. Se discuten las formas de ocupación del espacio urbano, y los procesos de estigmatización e invisibilidad social de estas personas, traducidos en los conflictos cotidianos con órganos e instituciones del estado proporcionando servicios de asistencia social, salud y seguridad pública y ciudadanos domiciliados. Los datos apuntan al incremento en el número de personas en esta condición en Porto Alegre, permanecen más tiempo en la calle y el envejecimiento de esta población, lo que plantea interrogantes sobre las políticas públicas desarrolladas para este segmento.

Palabras-clave: Población adulta en la situación callejera; Porto Alegre; Estigmatización; Invisibilidad social.

\section{Introdução}

Dentre os grupos sociais que integram a cidade e constituem sujeitos de investigação sociológica, figuram as "pessoas em situação de rua", categoria social complexa e em construção, cujo lugar na cotidianidade transita entre o visível e o invisível. O uso do termo "pessoa em situação de rua" busca superar as limitações de termos como "morador de rua", que os situa como um grupo fixado numa condição específica, caracterizada por um conjunto de carências. Enfatiza-se assim "a situacionalidade da experiência nas ruas", "definindo-os a partir de uma concepção do habitar a rua como uma forma de vida possível" (Schuch e Gehlen, 2012, p. 17), sem essencializar essa condição e dando visibilidade às múltiplas formas de entrar, ficar, estar, usar, reivindicar e, também, sair da rua.

O imaginário social concebe as pessoas que fazem da rua o seu local de permanência, de moradia e sobrevivência, ainda que temporariamente, como um grupo homogêneo, de indivíduos caracterizados pela pobreza que utilizam espaços públicos para dormir, comer, consumir bebidas alcóolicas e drogas e fazer as necessidades fisiológicas, reduzindo a percepção do que se faz e 
de como se utiliza o espaço da rua à falta de recursos, à falta de domicílio próprio ou regular e à falta de higiene. Cria-se, assim, uma enorme distância social, marcada pelas fronteiras corporais "da sujeira, do corpo abjeto que assusta e afasta" (Frangella, 2005, p. 209), que separa o "morador de rua" e o "domiciliado", de tal forma que "tudo se passa como se elas não dispusessem de nenhuma forma de reconhecimento social positivo pautada em seus gestos ou suas formas de se vestir e falar" (Graeff, 2012, p. 762). Contudo, os próprios atores sociais identificados nessa condição vêm, aos poucos, se organizando e se mobilizando, inclusive nacionalmente, a fim de reivindicarem direitos e políticas públicas específicas. O surgimento do Movimento Nacional da População em Situação de Rua (MNPR) é sintomático desse movimento e parte das políticas atuais vigentes em Porto Alegre resultou dessa organização. ${ }^{1}$

No imaginário social, as representações da "rua" estabelecem fronteiras simbólicas que delimitam práticas aceitáveis neste espaço. Da Matta explorou as dimensões simbólicas deste par em oposição, analisando como são construídas as regras informais e implícitas do que é próprio de cada espaço:

Por tudo isso, não se pode misturar o espaço da rua com o da casa sem criar alguma forma de grave confusão ou até mesmo conflito. Sabemos e aprendemos muito cedo que certas coisas só podem ser feitas em casa e, mesmo assim, dentro de alguns dos seus espaços (Da Matta, 1997, p. 50).

Certas práticas não devem ser feitas na "rua", à vista dos outros, o que torna esse espaço interdito para o uso nas funções próprias da "casa". Simbolicamente, a rua é o espaço em "que devem viver os malandros, os meliantes, os pilantras e os marginais em geral" (Da Matta, 1997, p. 55) e, portanto, lugar de risco e perigo em oposição à proteção oferecida pela casa. Daí a percepção de anormalidade da apropriação dos espaços públicos e o seu não reconhecimento como formas de viver e estar no mundo. Para Magni (2006), trata-se de uma subversão da "ordem citadina", na qual a utilização de locais públicos para finalidades domésticas corrompe "a ordem de classificação (público/privado)" desses espaços.

${ }^{1}$ O MNPR impulsionou o desenvolvimento da Política Nacional para a População em Situação de Rua, política instituída em nível nacional por meio do decreto 7.053 de 2009, e possibilitou a formação dos Comitês Intersetoriais de Acompanhamento e Monitoramento das Políticas para as Pessoas em Situação de Rua (CiampsRUA), tanto em nível nacional, quanto estadual e municipal. Atualmente existem dois comitês instituídos do Rio Grande do Sul. A pesquisa na qual se baseia esse artigo constituiu uma ação do Plano Municipal de Enfrentamento à Situação de Rua e resultou também das reivindicações juntos aos gestores no Comitê Municipal de Acompanhamento e Monitoramento das Políticas para as PSR, feita pelos militantes e seus apoiadores (Campos et al., 2009, p. 184-5). 
Ao não se fixar às moradias que improvisa - o que pode ser voluntário ou não - a população que habita a rua não cria uma relação estável e de propriedade com o que a história da vida privada convencionou chamar de 'lar'. Praticamente não há onde exercer a privacidade; inexiste a propriedade que resguarda e preserva a família e os bens materiais. Evidencia-se, portanto, uma outra noção de moradia, mais flexível e transitória do que aquela acalentada pelo cidadão sedentário (Magni, 2006, p. 37).

As representações sociais de senso comum tendem a concebê-los ora pela perspectiva do abandono, da passividade e da impotência sendo, assim, "vítimas" das condições desiguais de existência, da precariedade da rede de proteção social do estado ou dos infortúnios da vida e, por essa razão, "merecedores de ajuda e caridade"; ora como responsáveis por sua própria condição, "sujeitos desviantes, vagabundos inadaptáveis ao trabalho e, portanto, ameaçadores da ordem pública por seu 'potencial criminoso"' (Lemões, 2013, p.41). Trata-se de uma condição social estigmatizada (Goffman, 1992), na qual os sujeitos são desacreditados ou associados aos "papeis sociais de drogado, de criminoso, de violento, de sujo e de doente" (Moura Jr. et al., 2013, p. 20), formas de ser e estar no espaço urbano não reconhecidas como legítimas e, portanto, aos quais "se nega o direito à cidade" (Resende, 2015, p. 121). A contradição está no fato de que a rua se torna lugar de conflito entre aqueles que fazem uso dela na condição de "casa" e aqueles que se apropriam dela como extensão de seus domicílios e estabelecimentos comerciais, fechando acessos a ruas sem saída em zonas residenciais, impedindo a permanência de pessoas nas calçadas em frente a lojas e bancos, entre outras práticas. É nessa relação dinâmica que se podem observar os conflitos que emergem das diferentes relações de poder entre os grupos sociais e suas diversas formas de ocupação dos espaços urbanos.

Neste artigo busca-se dar conta das condições sociais e materiais da população em situação de rua em Porto Alegre, capital do Rio Grande do Sul, a partir da análise comparativa dos dados levantados em 2007, 2008, 2011 e 2016, que tiveram como objetivo produzir um censo desta população no território municipal. Trata-se de analisar as mudanças no perfil desta população e identificar processos de estigmatização e produção de "invisibilidade social" das "pessoas em situação de rua". Os dados aqui apresentados são parte dos resultados da pesquisa quanti-qualitativa sobre a população em situação de rua de Porto Alegre, realizada em 2016. ${ }^{2}$

${ }^{2}$ Os dados estão publicados em relatório final da pesquisa Cadastro e Mundo da população em situação de rua de Porto Alegre, RS, 2016, disponível em <portoalegre.rs.gov.br/fasc/default. php?reg=41\&p_secao $=120>(26$ dez. 2018). 


\section{Metodologia de pesquisa}

A pesquisa consistiu da contagem (censo) da população nessa condição, da aplicação de um questionário, de tipo survey, a uma amostra dos adultos em situação de rua e de visitas etnográficas a centros de referência especializada em assistência social, Centros POP, ${ }^{3}$ albergues e abrigos municipais, bem como a realização de grupos focais com trabalhadores da Fundação de Assistência Social e Cidadania (Fasc) da prefeitura municipal de Porto Alegre. A pesquisa foi executada por pesquisadores do Instituto de Filosofia e Ciências Humanas da Universidade Federal do Rio Grande do Sul, em contrato firmado entre a Fasc/Prefeitura Municipal, com financiamento público, e a Ufrgs/Faufrgs. O projeto foi aprovado pelo Comitê de ética em pesquisa da Ufrgs e está registrada na Plataforma Brasil. ${ }^{4}$

As "pessoas em situação de rua" foram identificadas a partir das formas de utilização do espaço da rua ou de territórios subvertidos em sua utilização (habitação, perambulação, permanência ou outra forma de existência social), do uso dos serviços destinados a elas e da aparência e cultura material. Para isso, foi fundamental a presença de pessoas que vivem a condição da rua e, por isso, conhecem bem esse universo da cidade.

Definiu-se que fariam parte do universo do estudo, todas as pessoas que se encontrassem em abrigos e albergues destinados ao acolhimento e/ou abrigo temporário, intermitente ou definitivamente, bem como aquelas que se encontrassem em atividades de perambulação/ circulação pelas ruas e/ou que dissessem fazer da rua seu local de existência e habitação, mesmo que temporariamente (Gehlen et al., 2017a, p. 98).

A pesquisa contou com a interação entre pesquisadores, estudantes bolsistas da Ufrgs, profissionais da Fasc e outros órgãos da prefeitura de Porto Alegre, além de usuários dos serviços para pessoas em situação de rua, integrantes do MNPR e do jornal Boca de Rua. O processo de pesquisa também incluiu um curso de extensão, intitulado: População em situação de

\footnotetext{
${ }^{3}$ Os Centros POP em Porto Alegre constituem um Centro de Referência Especializado para População em Situação de Rua e tem por objetivo promover "o atendimento social com equipe multidisciplinar para adultos, idosos e famílias em situação de rua, de forma individualizada e coletiva, durante o período do dia, propondo aos usuários alternativas de enfrentamento à situação de rua e encaminhamentos junto a rede de serviços" < portoalegre.rs.gov.br/fasc/ default.php?p_secao $=116>$ ( 26 dez. 2018). Atendem cerca de 30 pessoas, em dois turnos, manhã e tarde.

${ }^{4}$ A pesquisa foi aprovada pelo Comitê de ética em pesquisa da Ufrgs em 11 de agosto de 2016 e está registrada na plataforma com o título: Pesquisa quanti-qualitativa da população adulta e infanto-juvenil em situação de rua da cidade de Porto Alegre.
} 
rua: lutas, políticas e desafios para as políticas públicas, chancelado pelo IFCH da Ufrgs, como atividade de qualificação de estudantes, de técnicos e de representantes da população em situação de rua e como preparação para as etapas de pesquisa quantitativa e qualitativa. A supervisão e acompanhamento foram realizados por profissionais da Fasc, da área de assistência social.

Os dados foram levantados em setembro e outubro de 2016, pela equipe executora da pesquisa, coordenada por pesquisadores dos departamentos de sociologia, antropologia e serviço social, com a participação de alunos dos cursos de Ciências Sociais e Políticas Públicas. Para o trabalho de campo foi imprescindível à atuação de usuários dos serviços públicos para pessoas em situação de rua, ligados ao MNPR e ao jornal Boca de Rua, como facilitadores da interação social com os entrevistados. Os facilitadores participaram das etapas de planejamento do trabalho de campo e de aplicação dos instrumentos, tendo recebido uma bolsa e financiamento para o transporte e alimentação. No total, seis facilitadores ligados à população em situação de rua e um profissional indicado pela Fasc atuaram na pesquisa, como apoiadores para o mapeamento e acompanhamento das equipes de campo, localizando onde estavam as pessoas e intermediando o contato dos entrevistadores com elas, sem participar diretamente das entrevistas (Gehlen et al., 2017a, p. 101).

O levantamento dos dados quantitativos foi realizado por meio da aplicação de dois instrumentos, baseados nos mesmos materiais utilizados nas duas pesquisas desse tipo realizadas anteriormente em 2007, 2008 e 2011, os quais já haviam sido testados. O primeiro consistiu no cadastro dos adultos em situação de rua em Porto Alegre, contemplando dados da entrevista, dados do entrevistado e dez perguntas referentes a características sociodemográficas e hábitos do cotidiano. Foi aplicado um questionário a uma amostra da população adulta em situação de rua em Porto Alegre, contemplando, além desses dados, 67 perguntas, referentes a informações sociodemográficas, hábitos cotidianos, renda e trabalho, relações familiares, saúde, sexualidade, violência e relação com instituições, perspectivas de futuro, além de três questões sobre as condições de realização da entrevista. ${ }^{5}$ Tanto o cadastro, como o questionário, foram objeto de reflexão e aprimoramentos durante o curso de extensão, no qual pesquisadores, alunos e bolsistas, bem como trabalhadores da Fasc e usuários dos serviços para pessoas em situação de rua.

\footnotetext{
${ }^{5}$ Essas questões serviram para obter um quadro das condições de realização do campo e consistia de três informações, anotadas pelo entrevistador, referentes às condições em que estava o entrevistado $(81,1 \%$ estava em plenas condições de responder as perguntas), seu contexto social ( $49,6 \%$ estava sozinho e $46,6 \%$ com outros adultos em situação de rua) e territorial $(27,5 \%$ estava instalado em lugar público, 23,8\% em trânsito ou trabalhando, 18,6\% perambulando, $14,5 \%$ descansando ou dormindo).
} 


\section{Perfil das pessoas em situação de rua na cidade de Porto Alegre ${ }^{6}$}

Ao final da pesquisa foram cadastrados 2.115 indivíduos adultos considerados em "situação de rua" na cidade de Porto Alegre. Em 2007, 2008 e 2011 foram cadastrados 1.203 e 1.347 pessoas, o que representa um aumento de $75,8 \%$ desde 2011. A grande maioria é do sexo masculino, percentual que passou de 81,8\% em 2007-2008 para 85,3\% em 2016, com diminuição de pessoas do sexo feminino. Em 2016, 34,4\% dos cadastrados se autodeclararam brancos, $24,6 \%$ pretos ou negros, $12,4 \%$ pardos, $2,8 \%$ indígenas, $0,8 \%$ amarelos e $24,5 \%$ outras denominações, dentre as quais se destaca a categoria "moreno" $(10,0 \%)$, o que sugere um percentual ainda maior da população negra e parda.

Tabela 1 - Distribuição percentual da população adulta em situação de rua de Porto Alegre, segundo sexo (2007-8, 2011 e 2016)

\begin{tabular}{lccc}
\hline Sexo & $\mathbf{2 0 0 7 - 8}$ & $\mathbf{2 0 1 1}$ & $\mathbf{2 0 1 6}$ \\
Masculino & 81,8 & 81,7 & 85,7 \\
Feminino & 18,2 & 17,1 & 13,8 \\
Não declarou/outro & - & 1,2 & 0,5 \\
Total & 100,0 & 100,0 & 100,0 \\
\hline
\end{tabular}

Fonte: Pesquisa Perfil e Mundo dos Adultos em Situação de Rua de Porto Alegre, 2007-8 (N=1203), $2011(\mathrm{~N}=1347)$ e $2016(\mathrm{~N}=1753)$.

Analisando os dados de 2007-2008, observa-se que a população entre 18 e 24 anos reduziu sua participação à metade, enquanto as faixas etárias de 35 a 44 anos e 45 e 59 anos aumentaram de $22,1 \%$ e $21,9 \%$, respectivamente, para $29,1 \%$ e $25,3 \%$ em 2016 . Os dados revelam que, paralelamente ao crescimento absoluto, há um processo de envelhecimento deste grupo social, pois mais de $60 \%$ da população em situação de rua de Porto Alegre tem 35 anos ou mais.

\footnotetext{
${ }^{6}$ Os dados apresentados referentes a 2016 se referem apenas às respostas válidas. As informações que, por razões diversas, como problemas na coleta das informações, decorrentes da situação de entrevista, negação de respostas consideradas individualmente por questão, entre outras, eventualmente não puderam ser coletadas, foram consideradas "inválidos" e não entraram no cálculo dos percentuais válidos de resposta. Algumas questões da amostra não foram aplicadas para todos os (as) entrevistados (as), pois estavam vinculadas a respostas de questões anteriores. Neste caso, foi informado o total de respostas para aquela questão, apresentando-se como o "N".
} 
Gráfico 1 - Distribuição percentual da população adulta segundo a faixa etária, Porto Alegre: 2007-8, 2011 e 2016

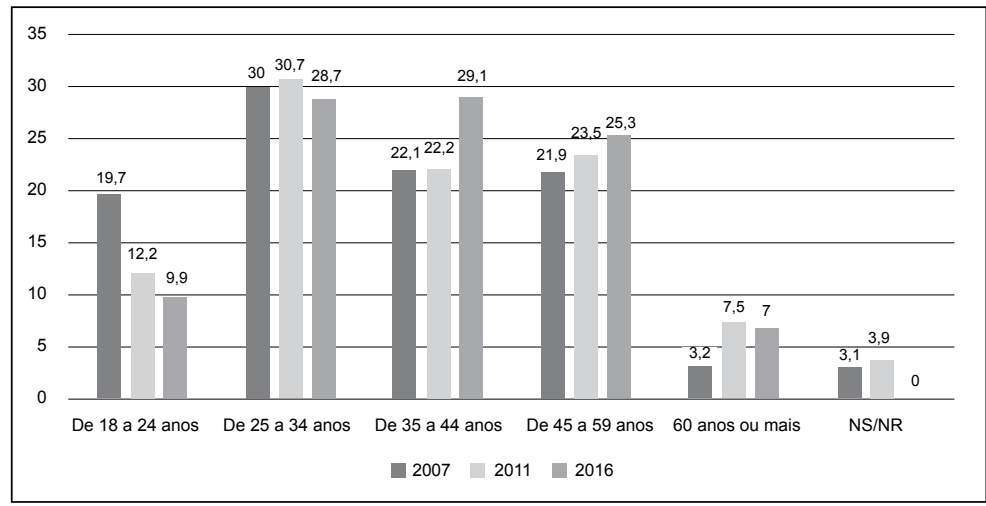

Fonte: Pesquisa perfil e mundo dos adultos em situação de rua de Porto Alegre, 2007-8 (N=1203), $2011(\mathrm{~N}=1347)$ e $2016(\mathrm{~N}=1721)$.

Considerando a naturalidade dos indivíduos cadastrados, 49,3\% nasceram em Porto Alegre e 9,8\% nasceram na região metropolitana. Entre os migrantes, $32,0 \%$ são do interior do estado e $6,9 \%$ de outros estados e $1,4 \%$ são imigrantes de outros países. O percentual de estrangeiros dobrou desde 2007-2008. Quanto ao tempo de moradia em Porto Alegre, pode-se verificar, na Tabela 2, que 24,7\% moravam em Porto Alegre há menos de cinco anos, sendo que, destes, $12,4 \%$ moravam há menos de um ano.

Tabela 2 - População adulta em situação de rua, segundo o tempo de moradia em Porto Alegre (2007-8, 2011 e 2016)

\begin{tabular}{|c|c|c|c|c|c|c|}
\hline \multirow{2}{*}{ Tempo } & \multicolumn{2}{|c|}{$2007-8$} & \multicolumn{2}{|c|}{2011} & \multicolumn{2}{|c|}{2016} \\
\hline & Freq & $\%$ & Freq & $\%$ & Freq & $\%$ \\
\hline Menos de 1 ano & 139 & 11,6 & 140 & 10,4 & 159 & 12,5 \\
\hline Entre 1 ano e um dia e 5 anos & 128 & 10,6 & 139 & 9,6 & 155 & 12,2 \\
\hline Entre 5 anos e um dia e 10 anos & 93 & 7,7 & 88 & 6,5 & 128 & 10,1 \\
\hline Entre 10 anos e um dia e 20 anos & 129 & 10,7 & 136 & 10,1 & 179 & 14,1 \\
\hline Mais de 20 anos & 262 & 21,8 & 270 & 20,0 & 647 & 51,1 \\
\hline Desde que nasceu & 341 & 28,3 & 164 & 34,4 & - & - \\
\hline Não lembra & 6 & 0,5 & - & - & - & - \\
\hline NR & 105 & 8,7 & 120 & 8,9 & - & - \\
\hline Total & 1203 & 100 & 1347 & 100 & 1268 & 100 \\
\hline
\end{tabular}

Fonte: Pesquisa Perfil e Mundo dos Adultos em Situação de Rua de Porto Alegre, 2007-8 (N=1203), $2011(\mathrm{~N}=1347)$ e $2016(\mathrm{~N}=1268)$. 
Os dados indicam, por um lado, mobilidade no território, especialmente do interior do estado para a capital e, por outro lado, a consolidação da moradia em Porto Alegre de grande parte da população adulta em situação de rua. De fato, houve aumento daqueles que calcularam entre 10 e 20 anos e mais de 20 anos de tempo de vida na rua, o que aponta a demanda de políticas públicas específicas para este grupo social.

Gráfico 2 - Distribuição percentual da população adulta, segundo o tempo em que está em situação de rua, Porto Alegre: 2007, 2008, 2011 e 2016

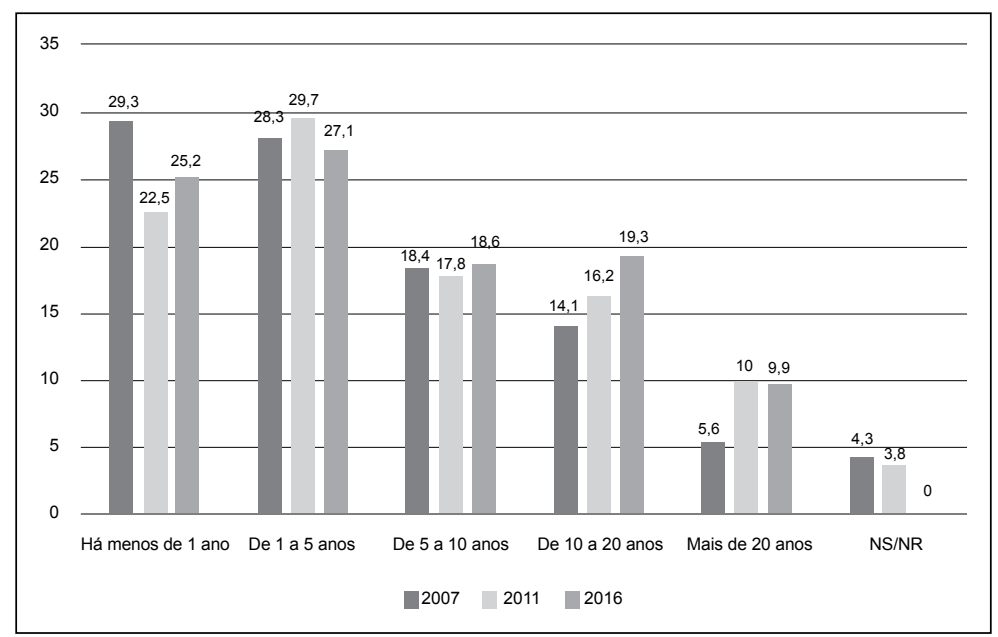

Fonte: Pesquisa Perfil e Mundo dos Adultos em Situação de Rua de Porto Alegre, 2007-8 (N=1203), $2011(\mathrm{~N}=1347)$ e $2016(\mathrm{~N}=1516)$.

Embora o percentual de analfabetos tenha decrescido em relação a 20072008 , passando de $16 \%$, para $6 \%$, a grande maioria $(57,4 \%)$ respondeu que não havia completado o ensino fundamental. Se considerarmos o percentual daqueles que completaram apenas o ensino fundamental, verifica-se que $70 \%$ dos adultos não completaram a escolaridade básica obrigatória.

A população de rua em Porto Alegre, em sua maioria, exerce alguma atividade que lhes proporciona renda e lhe atribui legitimidade social e de pertencimento à cidade (Gehlen et al., 2017b, p. 30). É importante ressaltar o percentual de pessoas que afirmaram passar o dia trabalhando $(17,8 \%)$. Quase todos, portanto, possuem alguma renda que, apesar de baixa, lhes garante alternativas de sobrevivência na rua, ainda que, em geral sejam atividades autônomas e de pouca estabilidade, como o trabalho envolvendo reciclagem 
$(23,9 \%)$, jardinagem $(14,0 \%)$, guardar e lavar carros $(12,8 \%)$ e pedir $(9,9 \%)$. Como reflexo disso, o rendimento mensal declarado pelos entrevistados é baixo: $69,8 \%$ recebem até um salário mínimo.

Tabela 3 - Escolaridade das pessoas em situação de rua (\%), Porto Alegre - 2007-8 e 2016

\begin{tabular}{lcc}
\hline Grau de escolaridade & $\mathbf{2 0 0 7 - 8}$ & $\mathbf{2 0 1 6}$ \\
Analfabeto & 16 & 6 \\
Ensino Fundamental incompleto & 46,4 & 57,4 \\
Ensino Fundamental completo & 13,4 & 12,8 \\
Ensino Médio incompleto & 8,7 & 9,7 \\
Ensino Médio completo & 6 & 9,9 \\
Ensino Superior incompleto & 1,9 & 1,6 \\
Ensino Superior completo & 0,7 & 0,8 \\
Pós-graduação & - & 0 \\
Nunca foi à escola & - & 1 \\
Aprendeu sozinho / Ensino Especial & 0,3 & - \\
NS/NR & 6,8 & 0,5 \\
Total & 100 & 100 \\
\hline
\end{tabular}

Fonte: Pesquisa Perfil e Mundo dos Adultos em Situação de Rua de Porto Alegre, 2007-8 $(\mathrm{N}=1203)$ e $2016(\mathrm{~N}=1598)$.

Tabela 4 - Distribuição percentual da população adulta em situação de rua de Porto Alegre, segundo o rendimento mensal

\begin{tabular}{lcc}
\hline Rendimento mensal & Frequência & $\%$ \\
\hline Até $1 / 2$ salário mínimo* & 146 & 38,2 \\
De mais de $1 / 2$ a 1 sm. & 121 & 31,6 \\
De mais de 1 a 1 e $1 / 2 \mathrm{sm}$. & 62 & 16,2 \\
De mais de 1 e $1 / 2$ a $2 \mathrm{sm}$. & 8 & 7,3 \\
De mais de 2 a $3 \mathrm{sm}$. & 22 & 5,7 \\
De mais de 3 a 4 sm. & 2 & 0,5 \\
Mais de 4 sm. & 2 & 0,5 \\
Total & 451 & 100 \\
\hline
\end{tabular}

* O salário mínimo em vigor no Brasil em setembro de 2016 era de $\mathrm{R} \$ 880,00$.

Fonte: Pesquisa Perfil e Mundo dos Adultos em Situação de Rua de Porto Alegre, 2016 (N=451). 
Em relação ao cotidiano nas ruas, a maioria $(53,8 \%)$ ainda se utiliza de lugares de risco e improvisados e com forte exposição ao ambiente natural, como praças, parques, calçadas, marquises, pontes, viadutos e rua. Em 2016, o uso como primeira opção dos espaços institucionalizados para pernoitar foi declarado por $37,4 \%$ dos entrevistados e como segunda, por $22,7 \%$. Os albergues têm maior procura $(23,7 \%$ e $10,3 \%$ respectivamente). É provável que o pequeno incremento da utilização dos albergues como dormitório tenha relação com a diminuição do uso de abrigos, para o qual é necessário passar pelo Núcleo de Acolhimento, criado em 2011. Esse dado aponta para o uso de serviços mais transitórios e pontuais, já que o acesso aos albergues não passa por esse Núcleo.

Tabela 5 - Locais utilizados com maior frequência como dormitório, 1 e e 2 o lugar - Porto Alegre: 2007-8 e 2016.

\begin{tabular}{lcccc}
\hline \multirow{2}{*}{ Locais utilizados para dormir } & \multicolumn{2}{c}{$\mathbf{2 0 0 7 - 8}$} & \multicolumn{2}{c}{ 2016 } \\
\cline { 2 - 5 } & 1o lugar & 2o lugar & 1o lugar & 20 lugar \\
Calçadas / Marquises/ Abas / Rua & 20,5 & 7,8 & 26,4 & 16,2 \\
Praças / Parques/ Aldeia & 18,9 & 9,1 & 15,7 & 10,4 \\
Albergue & 18,9 & 6,7 & 23,6 & 10,3 \\
Pontes / viadutos & 10,6 & 5,2 & 11,7 & 8,8 \\
Abrigos & 6,1 & 4,4 & 3,9 & 3,8 \\
Na própria casa & 4,5 & 1,5 & 4 & 1,2 \\
Hotéis / Pensões & 3,2 & 1,8 & 4 & 3,5 \\
Na casa de amigos / parentes & 3,1 & 2,7 & 1,9 & 3,9 \\
Locais abandonados / mocós & 2,7 & 1,6 & 1,9 & 1,7 \\
Terminal/Ponto de ônibus/Estação & 1,3 & 0,3 & 1,4 & - \\
Aluguel social & - & - & 0,3 & - \\
Vários locais & 0,7 & 0,2 & - & - \\
Outros locais & 3,3 & 3 & 1,3 & 6,6 \\
Dorme sempre no 1o lugar & - & 48,8 & - & - \\
NR & 6,2 & 6,9 & 3,9 & 33,6 \\
Total & 100 & 100 & 100 & 100 \\
\hline
\end{tabular}

Fonte: Pesquisa Perfil e Mundo dos Adultos em Situação de Rua de Porto Alegre, 2007-8 (N=1203) e 2016 (N: $1^{\circ}$ lugar $=1658 ; \mathrm{N}: 2^{\circ}$ lugar $=1074$ ).

Os locais preferidos para passar o dia são as ruas, as calçadas, marquises, esquinas, parques, praças, pontes e viadutos. Apenas 9,5\% dos entrevistados 
disseram como primeira opção os Centros POP $(6,3 \%)$, Creas/Cras $(1,2 \%)$, Escola de Porto Alegre ${ }^{7}$ (EPA) (1,6\%) e Caps-AD (0,1\%). Assim, os equipamentos públicos pouco incidem nas escolhas dos locais e sobre o uso do tempo por onde transita a população quando esta não está dormindo, o que pode contribuir para a grande visibilidade deste público na cidade de Porto Alegre.

Tabela 6 - Locais onde passam a maior parte do tempo quando estão acordados, 1 e e $2^{\mathrm{o}}$ lugar - Porto Alegre: $2007-8$ e 2016

\begin{tabular}{lccccc}
\hline Locais onde passam a maior & \multicolumn{2}{c}{$\mathbf{2 0 0 7 - 8}$} & \multicolumn{2}{c}{$\mathbf{2 0 1 6}$} \\
parte do tempo & $\mathbf{1}$ lugar & $\mathbf{2}$ lugar & $\mathbf{1}$ logar & 2o lugar \\
Praças / Parques / Pontes / Viadutos & 38,8 & 17,8 & 17,3 & 12,5 \\
Trabalho / Procurando trabalho / esquina & 9,5 & 1,83 & 17,8 & - \\
Pelas ruas / perambulando / calçados / & 24,7 & 18,8 & 33,2 & 19,1 \\
marquises & & & 1 & 1,2 \\
Sinaleira & 9,8 & 5,7 & 0,3 & 1,3 \\
Casas de convivência / Abrigos & 4,1 & 5,2 & 0,1 & 0,5 \\
Beira do rio / Gasômetro & 2,1 & 0,8 & 0,7 & 2 \\
Ponto do ônibus / Terminal de ônibus / & & & \\
Rodoviária & 3,1 & 2,1 & 1,6 & 1,1 \\
Em frente a comércio & - & - & 6,3 & 4,4 \\
Centro POP & - & - & 1,2 & 0,8 \\
CAPS AD & - & - & 1,6 & 0,6 \\
EPA & - & - & 0,1 & - \\
CREAS/CRAS & 1,6 & - & - & - \\
Ceasa / Mercado Público & 0,6 & 1 & 0,6 & - \\
Biblioteca / Casa de Cultura & 1 & 0,3 & 0,7 & - \\
Vila / Em casa & 4,7 & 3,9 & 7,1 & 20,5 \\
Outros & 1 & 42,7 & 10,4 & 36 \\
NR & 100 & 100 & 100 & 100 \\
\hline Total &
\end{tabular}

Fonte: Pesquisa Perfil e Mundo dos Adultos em Situação de Rua de Porto Alegre, 2007 (N: 1임 lugar=382, $\mathrm{N}: 2^{\circ}$ lugar=382) e $2016\left(\mathrm{~N}: 1^{\circ}\right.$ lugar=1758, N: $2^{2}$ lugar=1108).

As estratégias utilizadas para se alimentar e fazer a higiene são variadas: mais da metade (52\%) obtém alimento em instituições públicas e privadas, leigas ou religiosas e cerca de $25 \%$ mencionou que consegue comida pedindo

${ }^{7}$ A Escola Municipal de Ensino Fundamental de Porto Alegre (EPA) é um serviço especializado da Secretaria Municipal de Educação (Smed) especializada em Educação de Jovens e Adultos (EJA). 
diretamente em residências, estabelecimentos comerciais e cozinhas. A dificuldade para conseguir um local para realizar sua higiene pessoal e fazer suas necessidades fisiológicas é apontada como um dos principais fatores que interferem no cotidiano das pessoas em situação de rua, causando desconforto e inviabilizando até mesmo a manutenção de atividades remuneradas regulares. Menos da metade (40,1\%) afirmou utilizar instituições assistenciais previstas para a sua acolhida, como albergues, abrigos, Centros POP ou Caps. Banheiros e chuveiros públicos constituem a segunda resposta mais repetida $(22,5 \%)$. Praças, parques, calçadas e ruas, assim como rios, córregos e arroios correspondem a $15,0 \%$ das respostas, e os espaços privativos, como a própria casa, hotéis e pensões, ou então a casa de amigos, parentes ou conhecidos somam 12,0\%. Aparecem ainda espaços de grande circulação pública (postos de gasolina, bares, hospitais, rodoviária com $5,4 \%$ de respostas).

Com relação à pergunta estimulada acerca dos serviços públicos e instituições mais utilizadas, as respostas mostram a grande procura por instituições religiosas $(48,9 \%)$, pelo restaurante popular $(48,8 \%)$ e o Sopão Ramiro d'Ávila (39,8\%), tradicional entidade assistencial de Porto Alegre. Também ganham importância os albergues, os Centro POP e o Consultório na Rua, cujos serviços são voltados especialmente para essa população. Entretanto, cabe ressaltar que mais da metade (51\%) dos respondentes afirmou não utilizar albergues e $71,2 \%$ não utiliza abrigos.

Gráfico 3 - Distribuição percentual do uso de serviços públicos em Porto Alegre - 2016

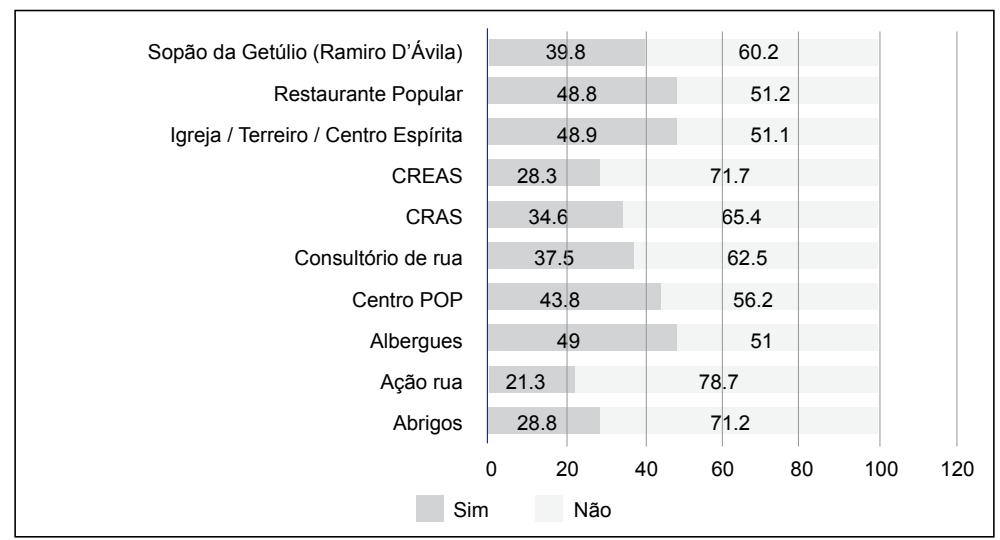

Fonte: Pesquisa Perfil e Mundo dos Adultos em Situação de Rua de Porto Alegre, 2016 (N: igreja=440; $\mathrm{N}$ : abrigos $=441 ; \mathrm{N}$ : albergues $=443 ; \mathrm{N}$ : Centro $\mathrm{Pop}=445 ; \mathrm{N}$ : restaurante $=443 ; \mathrm{N}$ : sopão $=440$; $\mathrm{N}$ : consultório=440; N: Ação Rua=433; N: CREAS=438; N: CRAS=434). 
As formas de estigmatização e discriminação das pessoas em situação de rua aparecem nos motivos para não utilizarem albergues e abrigos. A maior parte das respostas $(30 \%)$ se refere às regras rígidas, que estabelecem horários rigorosos para entrar e sair, impedem que casais e famílias se acomodem juntos, proíbem o uso de álcool e drogas e, também, a entrada de animais de estimação, entre outras normas que afastam os usuários do serviço. Em segundo lugar $(15,6 \%)$ aparecem as formas de tratamento dos monitores e funcionários, que incluem racismo, discriminação, preconceito, violência, na forma de agressões físicas e verbais. Em seguida, destaca-se a dificuldade de conseguir vagas e a localização dos albergues, concentrados na região central.

Tabela 7 - Principais motivos para não usar albergues/abrigos, Porto Alegre - 2016

\begin{tabular}{lc}
\hline Principal motivo & $\mathbf{2 0 1 6}$ \\
Regras rígidas, falta de liberdade, suspensão & 21,2 \\
Forma de tratamento pelos administradores/hostilidade interna & 15,6 \\
(Vítima de racismo, maus tratos/violência, preconceito...) & 12,8 \\
Dificuldade em conseguir vagas/longe/localização & 12,2 \\
Horários & 9,1 \\
Não conhece albergues, nunca precisou, prefere a rua & 5,2 \\
Proibição de uso de álcool e/ou drogas & 2,4 \\
Limitação do local para guardar o instrumento de trabalho ou & 1,8 \\
acolher o animal de estimação & 1,2 \\
Falta de documentos & 0,9 \\
Doença & 5,4 \\
Proibição de sexo & 12,2 \\
Outro & 100 \\
NSA/NR & 1,2 \\
Total & \\
\hline
\end{tabular}

Fonte: Pesquisa Perfil e Mundo dos Adultos em Situação de Rua de Porto Alegre, 2016 (N=328)

$\mathrm{Na}$ situação de entrevista, procurou-se compreender os processos que levaram à situação de rua. Segundo Gehlen et al. (2017b), a condição de rua é resultado de processos históricos complexos, multicausais, cujo início muitas vezes resulta de rupturas nas dimensões afetivas, familiar, social e profissional, mas também pela dependência de substâncias como álcool, drogas e medicamentos. De forma sintética, os principais motivos apontados pelos entrevistados para terem ido para a rua são as questões relacionadas ao alcoolismo e ao uso de drogas $(24,9 \%)$ e variáveis relacionadas à instabilidade e à ruptura familiar. Essa hipótese pode ser reforçada pelo 
papel que as separações e decepções amorosas têm nesse processo (10,0\%), que podem levar a sentimentos de desilusão, à depressão e podem estar também relacionadas ao uso de álcool e drogas. Destaca-se a preponderância das relações familiares nas motivações apresentadas, tanto nas alternativas colocadas no questionário, quanto nas "outras motivações" que os próprios entrevistados forneceram. Se considerarmos que as "separações e decepções amorosas", "os maus tratos na família", "não se sentir bem com a família", "a morte de algum familiar", o "envolvimento da família com o tráfico de drogas" e "o uso de drogas ou o alcoolismo na família de origem" são situações que envolvem pessoas próximas ou do núcleo familiar de origem, verificamos que $33,7 \%$ das motivações explicitadas pelos entrevistados envolveram questões e conflitos familiares. De fato, algumas pessoas explicitaram que a decisão de irem para rua se deveu em grande parte ao próprio envolvimento com drogas ou álcool e a uma decisão de preservar a família em relação aos danos e conflitos que a dependência gerava, o que nos leva a apontar para pesquisas futuras a investigação mais apropriada de uma correlação entre variáveis de instabilidade familiar e problemas com álcool e drogas.

Tabela 8 - Principais motivações para terem ido para a rua, Porto Alegre - 2016

\begin{tabular}{lcc}
\hline Por que / como veio para a rua & Freq & \% \\
Uso de drogas / Alcoolismo próprio & 112 & 24,9 \\
Conflitos e / ou maus tratos na família (violência) & 56 & 12,5 \\
Separação / decepção amorosa & 45 & 10,0 \\
Desemprego & 40 & 8,9 \\
Por causa da morte de algum familiar & 33 & 7,4 \\
Não tem família / não se sente bem na família & 26 & 5,8 \\
Perda da moradia & 23 & 5,1 \\
Por que gosta / por opção & 23 & 5,1 \\
Foi expulso de casa & 14 & 3,1 \\
Uso de drogas / Alcoolismo na família de origem & 13 & 2,9 \\
Endividamento / falta de dinheiro & 10 & 2,3 \\
Sofre ameaças / jurado na comunidade & 9 & 2,0 \\
Saída do Sistema Penitenciário (Prisões) & 7 & 1,6 \\
Porque estava doente & 5 & 1,1 \\
Porque a família está envolvida com o tráfico & 4 & 0,9 \\
Saída da FASE / FEBEM & 1 & 0,2 \\
Outro & 28 & 6,2 \\
Total & $\mathbf{4 4 9}$ & $\mathbf{1 0 0}$ \\
\hline
\end{tabular}

Fonte: Pesquisa Perfil e o Mundo dos Adultos em Situação de Rua de Porto Alegre, 2016. (N=449). 
O conjunto de respostas revela, assim, uma miríade de fatores associados às circunstâncias pessoais e à própria trajetória individual dos sujeitos, o que dificulta a percepção dos fatores estruturais e das vulnerabilidades a que os atores sociais podem estar sujeitos e atuam tanto no sentido de configurar processos de exclusão social, quanto processos de reforço e prolongamento da situação de rua, inviabilizando ou mesmo impedindo a ruptura com as carências múltiplas.

\section{Processos de estigmatização e invisibilidade social}

De fato, há um conjunto de aspectos bastante negativos em relação à rua que são apontados pelos entrevistados e são bastante reveladores das vulnerabilidades, riscos e perigos a que estão expostos. A pergunta $O$ que menos gosta na rua? evidencia os conflitos que emergem no âmbito da vivência dessa condição: 20,1\% se referiram às brigas entre as pessoas que estão na rua com principal aspecto (1 $1^{\mathrm{a}}$ opção) e 16,7\% aos roubos e furtos de seus pertences ( $2^{\underline{a}}$ opção), na disputa por espaços de convivência, abrigo e obtenção de recursos. Porém, em seguida destacam-se os processos de estigmatização e invisibilidade social experimentados pelos entrevistados, especialmente no que diz respeito à produção e reprodução do estigma social de viver na rua. Entre os principais aspectos destacados está a "discriminação de estar na rua", que apareceu como a primeira opção para 19,8\% dos entrevistados.

Tabela 9 - Aspectos dos quais menos gostam na rua (1ª e $2^{\underline{a}}$ opção) (\%), Porto Alegre - 2016

\begin{tabular}{lcc}
\hline O que menos gosta na rua & \multicolumn{2}{c}{$\mathbf{2 0 1 6}$} \\
\hline As brigas entre as pessoas que estão na rua & $\mathbf{1}$ opção & $\mathbf{2}^{\mathbf{a}}$ opção \\
A discriminação de estar na rua & 20,1 & 15,4 \\
Ficar na chuva e no frio durante o inverno & 19,8 & 10,3 \\
A vigilância da polícia & 14,1 & 14,1 \\
Os roubos entre as pessoas que estão na rua & 11,8 & 8,3 \\
Nada & 10,8 & 16,7 \\
Falta de comida/fome & 10,5 & 4,5 \\
Outro & 4,2 & 8,3 \\
Falta de trabalho & 3,5 & 12,2 \\
Não ter endereço fixo & 2,6 & 6,4 \\
Total & 2,6 & 3,8 \\
\hline
\end{tabular}

Fonte: Pesquisa Perfil e o Mundo dos Adultos em Situação de Rua de Porto Alegre, 2016 (N: 1ª opção=313; $\mathrm{N}: 2^{\mathrm{a}}$ opção=156). 
O que mais chama atenção, mais do que a discriminação e a estigmatização, é a sensação de estar vulnerável à violência. A escolha da opção "a vigilância da polícia” que, na maioria das vezes, atua como de forma opressora em relação a essa população, foi apontada por $11,8 \%$ dos entrevistados em primeiro lugar e por $8,3 \%$ em segundo lugar. Analisando o conjunto de respostas categorizadas como "outros", 19,8\% das respostas se referem à violência e $6,2 \%$, à insegurança, como os elementos de que menos gostam na rua. Esses dados são reforçados nas respostas sobre seus principais medos: o medo de ser assassinado enquanto estão dormindo, foi manifestado por $13,2 \%$ e $8,5 \%$ dos entrevistados. Um em cada 5 entrevistados, portanto, tem medo de morrer de forma violenta, incluindo aí o medo de ser queimado vivo. Em seguida, aparecem as agressões, que superam inclusive o medo da polícia.

Tabela 10 - Principais medos dos entrevistados em relação à rua, Porto Alegre - 2016

\begin{tabular}{lc}
\hline Principais medos & $\%$ \\
Ser morto/assassinado/dormir e não acordar no outro dia & 21,6 \\
Nada & 21,1 \\
Outro & 18,4 \\
Ser agredido & 14,4 \\
Da polícia & 12,7 \\
Ser roubado/assaltado & 9,6 \\
Ser violentado sexualmente & 2,2 \\
Total & 100 \\
\hline
\end{tabular}

Fonte: Pesquisa Perfil e o Mundo dos Adultos em Situação de Rua de Porto Alegre, 2016 (N=450).

Todos esses medos são fundamentados nas experiências de violência acumuladas pelos entrevistados, que se manifestam no conjunto de violências praticadas cotidianamente e, também, em violências que marcaram suas trajetórias de vida em relacionamentos anteriores, no âmbito familiar e das relações conjugais - grande maioria dos entrevistados $(60,6 \%)$ afirmou já ter sofrido algum tipo de violência, sendo que $47,5 \%$ foi vítima de violência mais de uma vez. Quando perguntados sobre quem praticou mais vezes, os entrevistados se referiram, em primeiro lugar, a agentes do estado, nomeadamente policiais da Brigada Militar, mas também policiais civis e agentes municipais, como funcionários do Departamento Municipal de Limpeza Urbana (DMLU) e da Secretaria Municipal do Meio Ambiente (Smam). 
Tabela 11 - Atores sociais identificados como praticantes de violência contra a PSR (1ํㅡ e 2 ${ }^{\underline{a}}$ opção) (\%), Porto Alegre - 2016

\begin{tabular}{lcc}
\hline Quem praticou mais vezes & $\mathbf{1}^{\mathbf{a}}$ opção & $\mathbf{2}^{\mathbf{a}}$ opção \\
Brigadianos & 31,4 & 25,4 \\
Outros grupos de rua & 23,6 & 20,1 \\
Pessoas desconhecidas & 15,9 & 16,4 \\
Familiares & 7,8 & 4,5 \\
Companheiro(a) & 5,0 & 6,0 \\
Outro & 5,0 & 3,0 \\
Moradores das casas e apartamentos & 4,3 & 7,5 \\
Policiais civis & 3,1 & 8,2 \\
Traficantes & 2,7 & 3,7 \\
Funcionários DMLU/SMAM & 0,4 & 0,7 \\
Segurança privada & 0,4 & 1,5 \\
Guarda municipal & 0,4 & 3,0 \\
Total & 100 & 100 \\
\hline
\end{tabular}

Fonte: Pesquisa Perfil e o Mundo dos Adultos em Situação de Rua de Porto Alegre, 2016. (N: 1ª opção=258; $\mathrm{N}: 2^{\underline{a}}$ opção=134).

Dos entrevistados, 70,5\% afirmou já terem sido detidos pela polícia, sendo que $23,5 \%$ uma vez e $47,0 \%$ mais de uma vez. Entre os principais motivos de detenção estão os delitos relacionados ao patrimônio, como roubos, assaltos, furtos e danos (26,5\%). Porém, quase um quarto $(24,2 \%)$ dos entrevistados relatou ter sido detido pelo fato de estar na rua, por engano ou denúncias da vizinhança, ou seja, sem terem cometido um delito, estando sujeitos, portanto, à estigmatização que a situação de rua provoca. A rotulação das pessoas em situação de rua como "suspeitas" ou como prováveis criminosos, especialmente pela polícia, aparece nas respostas daqueles que responderam terem sido detidos por outros motivos, por serem suspeitos $(12,1 \%)$ ou por preconceito $(6,1 \%)$.

As violências sofridas também se manifestam de formas simbólicas, nos processos de rotulação e estigmatização, pelas pessoas que têm moradia regular (casas, apartamentos, imóveis próprios ou alugados) ou são proprietárias ou trabalhadoras em locais públicos, especialmente estabelecimentos comerciais. A hostilidade em relação à presença de pessoas dormindo, ocupando, habitando ou fazendo outros usos dos espaços públicos contíguos, em frente ou imediatamente próximos de lojas, restaurantes, bancos, supermercados etc., resulta, muitas vezes, na adoção de estratégias veladas e, também, explícitas 
de invisibilização, cerceamento e, também, expulsão propriamente dita. A análise das situações e dos locais aos quais os entrevistados já tiveram o seu acesso barrado ou impedido, revelou um conjunto de experiências negadoras do reconhecimento social destes indivíduos como cidadãos com direitos equivalentes aos demais, sobretudo em relação aos espaços públicos, como praças, parques e transportes coletivos.

Gráfico 4 - Locais dos quais já foram barrados ou impedidos de estar (\%) - Porto Alegre, 2016

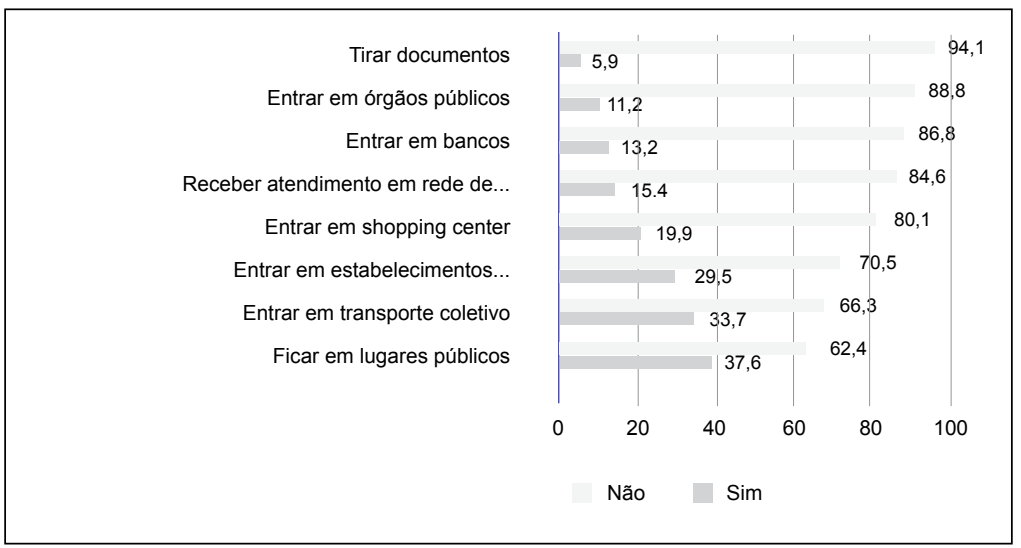

Fonte: Pesquisa Perfil e o Mundo dos Adultos em Situação de Rua de Porto Alegre, 2016. $(\mathrm{N}$ : lugares públicos $=407 ; \mathrm{N}$ : transporte coletivo $=410 ; \mathrm{N}$ : estabelecimentos comerciais $=410$; $\mathrm{N}$ : shopping center $=408 ; \mathrm{N}$ : rede de saúde $=409 ; \mathrm{N}$ : bancos $=408 ; \mathrm{N}$ : órgãos públicos $=409 ; \mathrm{N}$ : tirar documentos $=408$ ).

Outros espaços onde são sistematicamente barrados ou impedidos de entrar são os estabelecimentos comerciais, shoppings e bancos. Cerca de $45 \%$ dos entrevistados afirmaram já terem sido expulsos de algum lugar, sendo que, das 171 respostas registradas, $36,5 \%$ se referiam a locais e órgãos públicos, como ruas, calçadas, praças, parques, marquises e até mesmo hospitais e postos de saúde. Em seguida, figuram os estabelecimentos comerciais, incluindo bancos $(21,1 \%)$. Muitas vezes, os entrevistados não se encontravam dentro dos estabelecimentos, mas estavam na frente da loja ou do banco e foram expulsos, o que é revelador das dinâmicas de apropriação do espaço público que interferem diretamente nas possibilidades e formas de ser e estar na cidade.

Os resultados perversos dessas práticas aparecem nas entrevistas na percepção dos informantes das formas como são tratados pela população de 
Porto Alegre em geral. Os tratamentos negativos foram consideravelmente mais frequentes que os tratamentos positivos. Dos entrevistados, 82,4\% sentem-se tratados "com desconfiança", 80,7\% "com medo" e 79,4\% "com preconceito", o que reforça a estigmatização. Em seguida, figuram as respostas para as categorias "com indiferença" (75,9\% de respostas positivas), o que reforça a invisibilidade social. Mais da metade, $51,8 \%$, afirmou ser tratados "sem respeito". Por outro lado, ações como as doações de roupas, alimentos e dinheiro, distribuição de comida, entre outras iniciativas assistenciais e de caridade, por parte de organizações não governamentais, voluntários, igrejas e outras instituições, ajudam a compor o conjunto de percepções de "solidariedade", vivenciadas por mais da metade $(58,2 \%)$ dos respondentes. Trata-se da única categoria positiva reconhecida pelos entrevistados; contudo, prevalecem as situações em que a desconfiança e o medo, subjacentes a "suspeita" em relação ao tipo social enquadrado na categoria de "morador de rua", geram situações concretas de discriminação com base no preconceito.

Tabela 12 - Locais dos quais os entrevistados foram expulsos (\%), Porto Alegre - 2016

\begin{tabular}{lc}
\hline Tipo de local & $\mathbf{\%}$ \\
Locais / órgãos públicos & 36,8 \\
Estabelecimentos comerciais / bancos & 21,1 \\
Outros & 10,5 \\
Albergues/centro pop / restaurante popular & 7,6 \\
Da própria casa / de pessoas próximas & 6,4 \\
(Igrejas / clubes / festas / bailes e agremiações) & 5,8 \\
Escolas / colégios/faculdades & 5,8 \\
Não sabe / não lembra & 3,5 \\
Transporte coletivo & 2,5 \\
Total & 100 \\
\hline
\end{tabular}

Fonte: Pesquisa Perfil e o Mundo dos Adultos em Situação de Rua de Porto Alegre, 2016 (N=171).

\section{Considerações finais}

Estar na rua é estar vulnerável às variações climáticas, aos desconfortos da falta de abrigo e privacidade, mas também ao insulto moral e à discriminação, à rejeição velada ou explícita dos que têm domicílio e, inclusive, dos profissionais dos setores públicos que se ocupam de quem não tem moradia 
regular. A vulnerabilidade, a experiência da violência e da discriminação afetam o corpo, a identidade e a percepção de mundo das pessoas em situação de rua. Não por acaso, despertam sentimentos de medo e insegurança e colocam essa população em um estado constante de alerta e tensão. A conflitualidade se manifesta não apenas entre aqueles que possuem habitação regular e os moradores de rua, mas também entre os membros desta população na disputa por espaços de convivência, abrigo e obtenção de recursos.

À condição precária dos corpos, à decadência material e à fragilidade psicossocial soma-se um imaginário de ameaças sociais aos estabelecidos (Valencio et al., 2010) que se estendem, inclusive, aos espaços onde ela se localiza (Moura Jr. et al., 2013), gerando práticas de discriminação e estratégias que, no limite, operam no cerceamento e na interdição de espaços públicos, interferindo em seu cotidiano e oprimindo-os de forma mais ou menos explícita. As formas de violência institucional perpetradas pelo próprio estado, como o fechamento de banheiros públicos ou interdição de vias e praças para passar as noites, incluindo estratégias como a construção de prédios sem marquises e colocação de grades em torno de igrejas e árvores, para impedir que as pessoas ali durmam ou urinem. Com base em justificativas como "o mau cheiro", o "incômodo visual" e a ameaça de maculação dos pontos turísticos e destruição do patrimônio histórico, constituem-se verdadeiras "tecnologias de expulsão" e configuram o que veio a se denominar "arquitetura anti-mendigo", materializando "representações de ameaça criadas a respeito desse segmento sobre a legalidade da cidade que se pretende funcional e hegemônica" (Frangella, 2005, p. 201).

A própria forma como a população em situação de rua é percebida influencia a produção discursiva acerca da vulnerabilidade social, obliterando qualquer possibilidade de apreensão dos processos que levam a essa condição. Assim, a naturalização da situação de rua, que deixa de ser percebida como um problema, e a sua concepção como "ameaça" passível de expurgo, "pode ter como efeito que deixe de ser percebida como uma injustiça à qual se deve responder com ação política" (Resende, 2015, p. 114). A questão não é apenas estrutural, mas também discursiva e reproduzida pelo discurso (da mídia, do senso comum).

As dificuldades de integração dessas pessoas nas formas de trabalho "regular", bem como a falta de endereço fixo e de um comprovante de residência dificultam, ou mesmo inviabilizam, o acesso ao conjunto de direitos trabalhistas, previdenciários e jurídicos que são prerrogativas da cidadania formalizada, representada pela posse de documentos, domicílio e registro em carteira. Isso contribui para que a população em situação de rua muitas vezes 
ocupe um lugar subalterno ou condição de subcidadania, onde não apenas seus direitos não são reconhecidos, como também são sistematicamente violados.

$\mathrm{O}$ estado mesmo pode alternar entre o foco nos direitos humanos das pessoas em situação de rua e o foco da segurança pública, "na qual o grupo é fonte de ameaça à ordem pública ao invés de ser visto como ameaçado por esta" (Valencio et al., 2010, p. 59). Tanto a falta ou a insuficiência de serviços adequados e especializados, como também medidas de interdição, restrição e controle dos usos do espaço público, configuram formas de violência institucional e simbólica que contribuem para a reprodução de desigualdades e para a vulnerabilização de determinados grupos sociais.

\section{Referências}

CAMPOS, Richard de; CAMPOS, Edson de; SILVA, Carlos Henrique da; STRAUBICHEN, José Luiz; PORTUGUEZ, Alexandre; GOMES, Cícero Adão; MACHADO, Veridiana Farias; VIEIRA, Margarete. A luta é constante: do movimento Aquarela da população de rua ao movimento nacional da população de rua do Rio Grande do Sul. In: Patrice Schuch; Ivaldo Gehlen; Rita dos Santos (orgs.). População de rua: políticas públicas, práticas e vivências. Porto Alegre: Cirkula, 2017. p. 183-197.

DA MATTA, Roberto. A casa e a rua: espaço, cidadania, mulher e morte no Brasil. Rio de Janeiro: Jorge Zahar Editor, 1987.

FRANGELLA, Simone Miziara. Moradores de rua na cidade de São Paulo: vulnerabilidade e resistência corporal ante as intervenções urbanas. Cadernos Metrópole, n. 13, p. 199-228, $2005<10.1590 / 8804>$.

GEHLEN, Ivaldo; MEIRELLES, Mauro; SCHUCH, Patrice. Desafios metodológicos ao estudar a população em situação de rua. In: Patrice Schuch; Ivaldo Gehlen; Rita dos Santos (orgs.). População de rua: políticas públicas, práticas e vivências. Porto Alegre: Cirkula, 2017a. p.91-107.

GEHLEN, Ivaldo; SCHUCH, Patrice; VIRGINIO, Alexandre; PIMENTA, Melissa de Mattos; MEIRELLES, Mauro. Dinâmicas, estratégias e mundo da população em situação de rua de Porto Alegre. In: Patrice Schuch; Ivaldo Gehlen; Rita dos Santos (orgs.). População de rua: políticas públicas, práticas e vivências. Porto Alegre: Cirkula, 2017b. p. 17-44.

GEHLEN, Ivaldo; SCHUCH, Patrice (orgs.). Relatório quanti qualitativo, contendo o cadastro censitário e o modo de vida cotidiana da população adulta em situação de rua de Porto Alegre. Porto Alegre: IFCH-Ufrgs, Fasc, 2016 <portoalegre.rs.gov.br/ fasc/default.php?reg=41\&p_secao $=120>(26$ dez. 2018).

GOFFMAN, Erving. Estigma: notas sobre a manipulação da identidade deteriorada. Rio de Janeiro: LTC editora, 1992.

GRAEFF, Lucas. Corpos precários, desrespeito e autoestima: o caso de moradores de rua de Paris-FR. Psicologia USP, v. 23, n. 4, p.757-775, $2012<10.1590 /$ S010365642012000400008>. 
LEMÕES, Tiago. A família, a rua e os afetos: uma etnografia da construção de vínculos entre homens e mulheres em situação de rua. São Paulo: Novas Edições Acadêmicas, 2013.

MAGNI, Cláudia Turra. Nomadismo urbano: uma etnografia sobre moradores de rua em Porto Alegre. Santa Cruz do Sul: Edunisc, 2006.

MOURA JR., James F.; XIMENES, Verônica M.; SARRIERA, Jorge C. Práticas de discriminação às pessoas em situação de rua: histórias de vergonha, humilhação e de violência em Fortaleza, Brasil. Revista de Psicologia, v. 22, n. 2, p. 18-28, 2013.

RESENDE, Viviane de Melo. Violência simbólica: representação discursiva da extrema pobreza no Brasil - relações entre situação de rua e vizinhança. Discurso \& Sociedad, v. 9, n. 1-2, p. 106-128, 2015.

SCHUCH, Patrice; GEHLEN, Ivaldo. A situação de rua para além de determinismos: explorações conceituais. In: Aline Espindola Dornelles; Júlia Obst, Marta Borba Silva (orgs.). A rua em movimento: debates acerca da população adulta em situação de rua na cidade de Porto Alegre: Editora do Brasil, 2012. p. 11-26.

VALENCIO, Norma; PAVAN, Beatriz J. R.; SIENA, Mariana; MARCHEZINI, Victor. Pessoas em situação de rua no Brasil: estigmatização, desfiliação e desterritorialização. In: Norma Valencio (org.) Sociologia dos desastres: construção, interfaces e perspectivas no Brasil, v. 2. São Carlos: RiMa, 2010. p. 53-72.

Recebido: 30 maio 2018

Aceito: 30 nov. 2018

Publicado: 01 mar. 2019

Endereço da autora:

Universidade Federal do Rio Grande do Sul

Departamento de Sociologia

Av. Bento Gonçalves, 9500, Agronomia

90650-670 Porto Alegre, RS, Brasil

Melissa De Mattos PimentA <melissampimenta@gmail.com>

Doutora em Sociologia pela Universidade de São Paulo (São Paulo, SP, Brasil). Professora adjunta do departamento de Sociologia da Universidade Federal do Rio Grande do Sul e membro permanente do Programa de pós-graduação em Sociologia da Universidade Federal do Rio Grande do Sul (Ufrgs, Porto Alegre, RS, Brasil).

Orcid: http://orcid.org/0000-0001-7817-6469 